\title{
PERIODONTAL DISEASE AS A RISK FACTOR FOR PRETERM DELIVERY IN INDIAN WOMEN
}

\author{
Sandhya Jain ${ }^{1}$, Seema Sharmaㄹ, Sonia Chawla ${ }^{3}$, Neelam B. Vaid ${ }^{4}$, Namita Kalra 5 , Amita Suneja ${ }^{6}$, Kiran Guleria7, Lovedeep Kaur ${ }^{8}$
}

${ }^{1}$ Associate Professor, Department of Obstetrics and Gynaecology, University College of Medical Sciences and GTB Hospital, Delhi. ${ }^{2}$ Ex-Postgraduate Resident, Department of Obstetrics and Gynaecology, University College of Medical Sciences and GTB Hospital, Delhi. ${ }^{3}$ Senior Resident, Department of Obstetrics and Gynaecology, University College of Medical Sciences and GTB Hospital, Delhi. ${ }^{4}$ Director Professor, Department of Obstetrics and Gynaecology, University College of Medical Sciences and GTB Hospital, Delhi. ${ }^{5}$ Director Professor and HOD, Department of Paedodontics \& Preventive Dentistry, University College of Medical Sciences and GTB Hospital, Delhi.

${ }^{6}$ Director Professor and HOD, Department of Obstetrics and Gynaecology, University College of Medical Sciences and GTB Hospital, Delhi.

${ }^{7}$ Director Professor, Department of Obstetrics and Gynaecology, University College of Medical Sciences and GTB Hospital, Delhi. 8Senior Resident, Department of Obstetrics and Gynaecology, University College of Medical Sciences and GTB Hospital, Delhi.

\section{BACKGROUND}

\section{ABSTRACT}

Preterm delivery resulting in birth less than 37 weeks occurs in approximately $12-15 \%$ of pregnancies. Many clinical studies indicate a positive correlation between periodontal disease and adverse pregnancy outcomes. Periodontal infections are preventable and treatable, therefore viewed as a modifiable factor. There are conflicting reports regarding efficacy of treating Periodontal Disease (PD) during pregnancy in reducing preterm labour. The study was designed to assess the possible relationship between periodontal disease and spontaneous preterm delivery.

\section{MATERIALS AND METHODS}

The present study was an observational case control study conducted in labour room and postnatal wards in the Department of Obstetrics \&Gynaecology in collaboration with Department of Dentistry in a tertiary care hospital. A total of 100 cases and 100 controls were recruited from labour room and screened for any evidence of periodontal disease within 72 hrs. of delivery by a dentist. Periodontal disease was scored using Periodontal Disease Index.

\section{RESULTS}

There was no significant difference in periodontal disease, in preterm group as compared to term group (62\% vs. $51 \%$ ). Out of 200 parturient recruited for the study, 113 had evidence of PD of varying severity (PDI $\geq 1$ to $\geq 4$ ). Whether the PD was mild or severe, there was no statistical difference in the occurrence of preterm delivery ( $\mathrm{p}$ value 0.892 ).

\section{CONCLUSION}

In the present study, we did not find any association between clinical periodontal disease, spontaneous premature delivery and small for gestational age (SGA).

\section{KEYWORDS}

Periodontal Disease, Preterm Labour, Periodontal Disease Score, SGA.

HOW TO CITE THIS ARTICLE: Jain S, Sharma S, Chawla S, et al. Periodontal disease as a risk factor for preterm delivery in Indian women. J. Evolution Med. Dent. Sci. 2016;5(88):6565-6569, DOI: 10.14260/Jemds/2016/1484

\section{BACKGROUND}

Preterm delivery resulting in birth less than 37 weeks occurs in approximately $12-15 \%$ of pregnancies. ${ }^{1}$ Of all preterm births, $40-45 \%$ are due to spontaneous preterm labour, 30 $35 \%$ follow premature rupture of membranes and rest are induced. ${ }^{2}$ Preterm infants are at elevated risk for morbidity and mortality. Early neonatal complications include infections, respiratory distress, intraventricular haemorrhage, retinopathy, necrotising enterocolitis, hypothermia, patent

Financial or Other, Competing Interest: None.

Submission 25-09-2016, Peer Review 22-10-2016,

Acceptance 28-10-2016, Published 02-11-2016.

Corresponding Author:

Dr. Sonia Chawla,

Senior Resident,

Department of Obstetrics and Gynaecology,

University College of Medical Sciences \&

GTB Hospital,

Delhi.

E-mail:drsonia0685@gmail.com

DOI: $10.14260 /$ jemds $/ 2016 / 1484$

\section{(c) (i) $\odot$}

ductus arteriosus and increased risk of hospitalisation. Late complications are neurodevelopmental disabilities, cognitive impairment and behavioural disorders. ${ }^{3-4}$ Along with immense physical and psychosocial pressure, it causes financial burden as well on the family, society and country at large. Successful reduction of perinatal morbidity and mortality associated with prematurity may require the implementation of effective risk identification and behavioural modification programs for prevention of preterm labour. There is increasing evidence that infections may play a role in $30-50 \%$ cases of preterm delivery. ${ }^{5}$ Many clinical studies indicate a positive correlation between periodontal disease and adverse pregnancy outcomes like preterm birth, premature prelabour, rupture of membranes, still birth, small for gestational age babies and pre-eclampsia. ${ }^{6-9}$

Periodontal disease refers to gingivitis (An inflammatory condition of the soft tissues surrounding a tooth or the gingiva) and periodontitis (Involving the destruction of such supporting structures as the periodontal ligament, bone, cementum or soft tissues). It is a chronic gram-negative and anaerobic bacterial infection of periodontium involving both 
direct tissue damage resulting from plaque bacterial products and indirect tissue damage through host inflammatory and immune responses, thus both local and systemic inflammation occur during periodontitis. ${ }^{10}$

It is proposed that periodontal bacteria and their virulence factors may gain access systemically via the blood circulation and reach the placenta. They initiate an inflammatory response at the feto-placental interface with the production of inflammatory cytokines. These cytokines in turn lead to excessive production of prostaglandins, which contribute to uterine contractions, premature prelabour rupture of the membranes and preterm delivery. Periodontal infections are preventable and treatable, therefore viewed as a modifiable factor. Integration of periodontal care into obstetric management may improve pregnancy outcome, as early intervention may reduce microbial challenge to oral tissues already altered due to hormonal changes.11 There are conflicting reports regarding efficacy of treating PD during pregnancy in reducing preterm labor. ${ }^{12-14}$ This case control study was designed to assess the possible relationship between periodontal disease and spontaneous preterm delivery.

\section{MATERIALS AND METHODS}

The present study was an observational case controlled study conducted in labour room and postnatal wards in the Department of Obstetrics and Gynaecology in collaboration with Department of Dentistry, UCMS and GTB Hospital, Delhi, during November 2011 to March 2013.

\section{Sample Size}

Assuming 11\% prevalence of periodontal disease among the controls and 1:1 ratio of case and control 100 cases and 100 controls required to detect an odd ratio of 3 with $90 \%$ power and 5\% level of significance. ${ }^{15-21}$ The study Group consists of 100 women recruited from labour room who were delivering prematurely between 28 and less than 37 weeks of gestation. Period of gestation was calculated based on last menstrual period. They were further divided into early preterm $(28$ to < 34 weeks of gestation) and late preterm ( 34 to $<37$ weeks of gestation) and were screened for any evidence of periodontal disease within 72 hrs. of delivery. Whereas in the control group, 100 women delivering at term ( $\geq 37$ wks. period of gestation) were recruited. They were also screened for evidence of PD within 72 hours of delivery. For each preterm delivery, successive term delivery patient was recruited. Inclusion criteria of study were: (1) Parturient women between 18 - 35 years of age, (2) Patient in active labour (cervix $\geq 3 \mathrm{~cm}$ dilated and $>80 \%$ effaced).

While exclusion criteria were history of rupture of membranes > 12 hours' duration, any medical or surgical condition, genitourinary tract infection and chorioamnionitis.

In addition to detailed systemic and obstetric examination, per speculum examination was done to rule out any lower genital tract infection and a high vaginal swab was also taken. Patients were monitored and managed as per departmental protocol during the course of labour and delivery and neonatal outcome was recorded. Dental examination was done by a dentist within $72 \mathrm{hrs}$. of delivery and periodontal disease was scored using Periodontal Disease Index.

Periodontal Disease Index (PDI): It is a modification of Russell's periodontal index developed by Ramfjord.10,22 It is intended to give an accurate assessment of a person's periodontal status.

Teeth to be examined: Maxillary right first molar (tooth \#16), Maxillary left central incisor (tooth \#21), Maxillary left first bicuspid (tooth \#24), Maxillary left first molar (tooth \#36), Mandibular right central incisor (tooth \#41), Mandibular right first bicuspid (tooth \#44). If any of the above teeth are missing or unerupted, then only the teeth present will be examined. PD has three components: Plaque, Calculus, Gingival and periodontal component.

$$
\text { PDI Score }=\frac{\text { Total score obtained after adding PDI score for all teeth examined }}{\text { No. of tooth examined }}
$$

\section{Interpretation}

- Minimum index: 0

- Maximum index: 6

- The higher the score the more severe the periodontal disease. In our study, PDI score of $\geq 1$ was taken as evidence of periodontal disease.

Data was analysed by Statistical Software SPSS Version 17.0. Association of PD with gestational age (preterm and term) was analysed using Chi-square test and Fisher's exact test. Preterm and term were stratified in two groups, SGA and AGA; and Chi-square test was used to compare proportion of PD in term and preterm.

Univariate logistic regression analysis was applied to find the odds ratio of risk factors. Power of the study: $90 \%$ Level of significance: $5 \%$ was used.

\section{OBSERVATIONS AND RESULTS}

This case-control study was performed on 200 women equally divided into two groups (Flow Chart 1). Socio-demographic characteristics of women in both study and control groups were comparable (Fig. 1). Regarding dental hygiene, the habit of brushing the teeth was similar in both the groups $(\mathrm{p}=$ 0.415), whereas practice of rinsing of mouth after meals once or twice was statistically higher in patients who delivered at term as compared to preterm (Table 1). The analysis of these dental hygiene activities in patients with PD in both the groups however did not show any statistical difference (Table 1). In present study although periodontal disease was higher in preterm group as compared to term group (62\% vs. 51\%, Fig. 2 ), but the difference did not reach statistical significance ( $\mathrm{p}=$ 0.117). Out of 200 parturient recruited for the study, 113 (preterm $62+$ term 51) had evidence of PD of varying severity (PDI $\geq 1$ to $\geq 4$ ).

Whether the PD was mild (PDI score $\geq 1$ - 2) or severe (PDI score $\geq 4$ ), there was no statistical difference in the occurrence of preterm delivery ( $\mathrm{p}$ value 0.892 ) (Fig. 3 ).

Irrespective of the presence of periodontal disease, majority of neonates were AGA $(72.6 \%$ in presence of periodontal disease and $80.5 \%$ in absence of PD). In patient with periodontal disease $26.5 \%$ neonates were SGA in comparison to $18.4 \%$ in patients without periodontal disease, although the difference was not statistically significant $(\mathrm{p}=$ 0.403) (Fig. 4). 


\begin{tabular}{|c|c|c|c|}
\hline $\begin{array}{c}\text { Dental History and } \\
\text { Examination }\end{array}$ & $\begin{array}{c}\text { Study } \\
\text { Group } \\
\text { (Preterm) } \\
(\mathbf{n = 1 0 0 )}\end{array}$ & $\begin{array}{c}\text { Control } \\
\text { Group } \\
\text { (Term) } \\
(\mathbf{n = 1 0 0 )}\end{array}$ & $\begin{array}{c}\mathbf{p} \\
\text { Value }\end{array}$ \\
\hline $\begin{array}{c}\text { Brushing of Teeth } \\
\text { No } \\
\text { Once } \\
\text { Twice }\end{array}$ & $\begin{array}{c}21(21 \%) \\
65(65 \%) \\
14(14 \%)\end{array}$ & $\begin{array}{c}14(14 \%) \\
72(72 \%) \\
14(14 \%)\end{array}$ & 0.415 \\
\hline $\begin{array}{c}\text { Rinsing of Mouth } \\
\text { after Meals } \\
\text { No } \\
\text { Once } \\
\text { Twice }\end{array}$ & $\begin{array}{c}28(28 \%) \\
18(18 \%)\end{array}$ & $\begin{array}{c}15(15 \%) \\
59(59 \%)\end{array}$ & 0.016 \\
\hline $\begin{array}{c}\text { Cases with Missed } \\
\text { Teeth }\end{array}$ & $27(27 \%)$ & $22(22 \%)$ & 0.411 \\
\hline $\begin{array}{c}\text { Cases with Caries } \\
\text { in Teeth }\end{array}$ & $35(35 \%)$ & $29(29 \%)$ & 0.363 \\
\hline \multicolumn{3}{|c|}{ Table 1: Dental History and Examination } \\
\hline \multicolumn{4}{|c|}{}
\end{tabular}

\begin{tabular}{|c|c|c|c|}
\hline $\begin{array}{c}\text { Dental } \\
\text { Hygiene } \\
\text { Activity }\end{array}$ & $\begin{array}{c}\text { Study } \\
\text { Group } \\
\text { (Preterm) } \\
(\mathbf{n = 6 2 *})\end{array}$ & $\begin{array}{c}\text { Control } \\
\text { Group } \\
\text { (Term) } \\
\text { (n= 51*) }\end{array}$ & $\begin{array}{c}\text { p } \\
\text { value }\end{array}$ \\
\hline $\begin{array}{c}\text { Brushing of Teeth } \\
\text { No }\end{array}$ & $20(32.3 \%)$ & $12(23.5 \%)$ & 0.168 \\
Once & $35(56.5 \%)$ & $37(72.5 \%)$ & \\
Twice & $7(11.3 \%)$ & $2(3.9 \%)$ & \\
\hline $\begin{array}{c}\text { Rinsing of Mouth } \\
\text { after Meals }\end{array}$ & & \\
No & $17(27.4 \%)$ & $9(17.6 \%)$ & 0.369 \\
Once & $37(59.7 \%)$ & $32(62.7 \%)$ & \\
Twice & $8(12.9 \%)$ & $10(19.6 \%)$ & \\
\hline \multicolumn{3}{|c|}{ Table 2: Comparison of Dental Hygiene Activities } \\
in Study and Control Groups with PD \\
\hline
\end{tabular}

*Parturient with evidence of PD

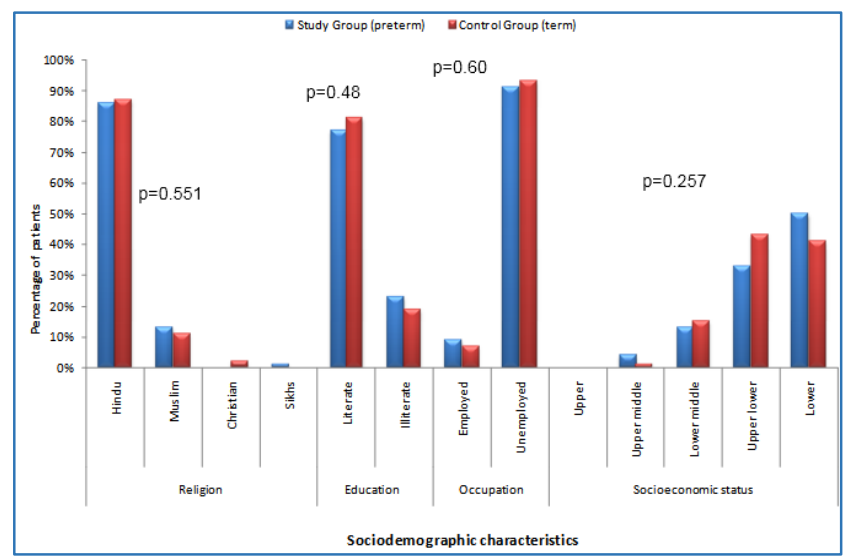

Figure 1. Demographic Characteristics in Study vs Control Groups

(Socio-demographic characteristics of women in study and control groups were comparable)

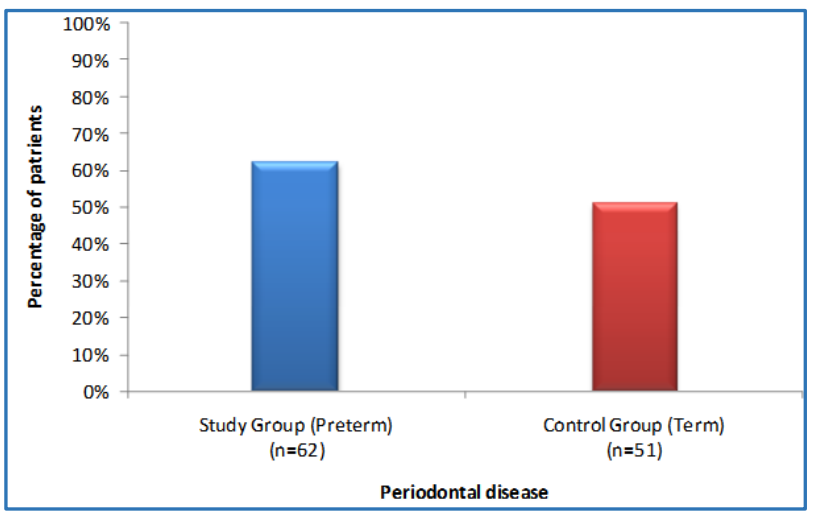

Figure 2. Evidence of Periodontal Disease in Study and Control Groups

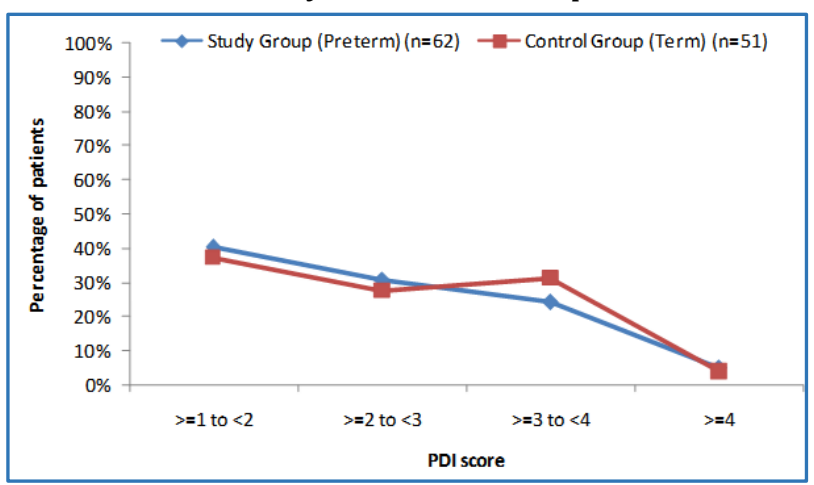

Figure 3. Comparison of the Prevalence of Preterm and Term According to Periodontal Disease Index (PDI) Score

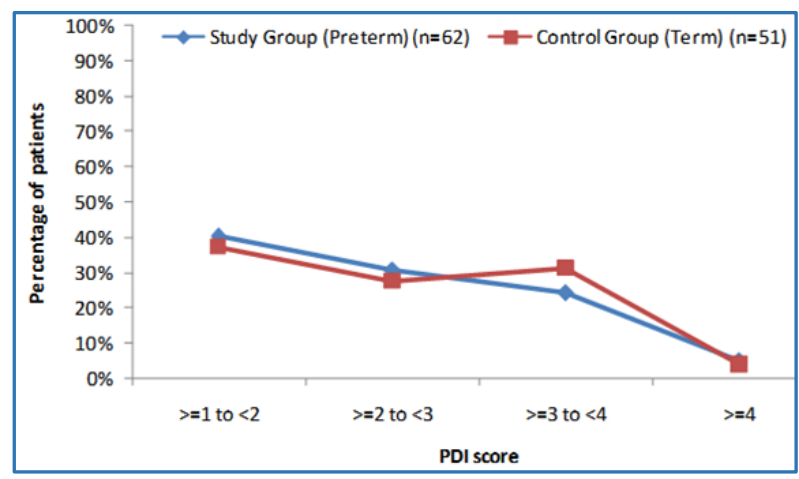

Figure 4. Comparison of Prevalence of SGA Births in Study and Control Groups

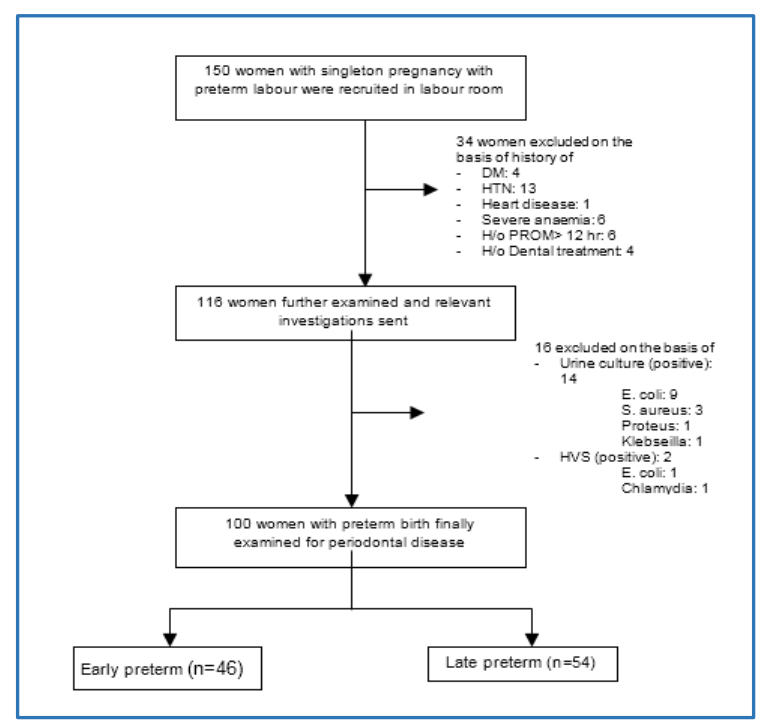

Flow Chart 1 


\section{DISCUSSION}

PTB is one of the most severe perinatal problems still persisting as a major cause of perinatal morbidity and mortality despite of years of research. In the present study both the groups were well matched with respect to age, religion education, occupation and socioeconomic status (Fig. 1). Although, periodontal disease was higher in preterm group as compared to term group ( $62 \%$ vs. $51 \%$, Fig. 2 ), but the difference did not reach statistical significance $(p=0.117)$. On literature search, numerous studies have reported conflicting results. Our results are consistent with various other studies, where no association was found between preterm birth and periodontal disease. Michalowicz et $\mathrm{al}^{23}$ reported in a large randomised trial to determine the impact of treatment of periodontal disease on preterm birth. They randomised over 800 patients and found no difference in preterm birth $(12 \%$ in treatment group versus $12.8 \%$ in control group), foetal growth restriction or low birth weight between the two groups. They also followed the improvement of periodontal disease and found that there was no change in the outcomes even after successful treatment of periodontal disease. In another large multicentre randomised controlled trial by Srinivas et $\mathrm{al}^{24}$ involving 800 patients, no benefit of treatment in terms of reduction of preterm birth $<35$ weeks $(8.6 \%$ in treatment group versus $5.5 \%$ in control group, $\mathrm{p}=0.11$ ), low birth weight, stillbirth or miscarriage was found. Conversely, the treatment group had a slightly higher rate of preterm birth, although that was not statistically significant. Offenbacher and Colleagues $^{25}$ also performed a multi-centre randomised treatment-masked controlled trial including 2000 patients and reported that there was no significant differences in the treatment group compared to the control group for preterm birth $(13.1 \%$ in treatment group versus $11.5 \%$ in control group, $\mathrm{p}=0.32$ ).

Positive associations between periodontal status and preterm birth alone, low birth weight or preterm birth associated to Low Birth Weight (PLBW) have been reported by cohort/cross-sectional studies by Offenbacher et al, Jeffcoat MK et al, ${ }^{7}$ Lunardelli and Peres, ${ }^{26}$ Gomes-Filho et al $^{27}$ and Khader et al. ${ }^{28}$ Similarly, there is no consensus regarding the benefit of dental therapy preventing preterm birth in the form of scaling and root planing during pregnancy in the literature. A meta-analysis of RCTs done by Polyzos et al ${ }^{29}$ in 2009 showed that treatment resulted in significantly lower preterm birth and borderline significantly lower low birth weight. The same authors in 2010 did another meta-analysis ${ }^{30}$ of 11 trials included 6558 women and showed that treatment of PD did not result in reducing the incidence of preterm birth. Literature is again inconsistent regarding the relationship of PD with SGA. Various authors have found no association between SGA and periodontal disease,24,30,31 whereas few others have reported a positive association. 32,33

Reasons for inconsistency in the results of association of PD with preterm birth may be because of large variation in the criteria used to define periodontal disease, as there is no universally accepted standard for periodontal disease. Most of the researchers have used their own case definitions that combined pocket depth and Clinical Attachment Level (CAL). Different studies used different criteria like Decayed, Missing and Filled Teeth (DMFT), Community Periodontal Index of Treatment Needs (CPITN) and the Russell Periodontal Index all of which have limited sensitivity for disease detection.
Secondly, potential bias may be due to the effect of confounders. Although some of the studies adjusted for race, socio-economic status and other important confounding variables by using multivariable regression analysis.

\section{CONCLUSION}

In the present study, we did not find any association between clinical periodontal disease, spontaneous premature delivery and SGA. Thus periodontal diseases do not appear to be a potential risk factor for preterm birth. With the present evidence, we do not encourage the routine use of screening of periodontal disease to reduce the risk of preterm birth.

\section{REFERENCES}

1. Dadhich JP, Paul VK. State of India's Newborns report. National neonatology forum and saving newborn lives/save the children. New Delhi: 2004.

2. Report of the National Neonatal-Perinatal Database. NNPD Network. Nodal Center: AIIMS, New Delhi. 200203.

3. Goldenberg RL, Culhane JF, Iams JD, et al. Epidemiology and causes of preterm birth. Lancet 2008;371(9606):7584.

4. Andrews WW, Cliver SP, Biasini F, et al. Early preterm birth: association between in utero exposure to acute inflammation and severe neurodevelopmental disability at 6 years of age. Am J Obstet Gynecol 2008;198(4): 466.e1-466.e11.

5. Goldenberg RL, Hauth JC, Andrews WW. Intrauterine infection and preterm delivery. $\mathrm{N}$ Engl J Med 2000;342(20):1500-7.

6. Offenbacher S, Katz V, Fertik G. Peridontal infection as a possible risk factor for preterm low birth weight. J Periodontol 1996;67(10 Suppl):1103-13.

7. Jeffcoat MK, Gerus NC, Reddy MS, et al. Periodontal infection and preterm birth: results of prospective study. J Am Dent Assoc 2001;132(7):875-80.

8. Goepfert AR, Jeffcoat MK, Andrews WW, et al. Periodontal disease and upper genital tract inflammation in early spontaneous preterm birth. Obstet Gynecol 2004;104(4): 772-83.

9. Mobeen N, Jehan I, Banday N, et al. Periodontal disease and adverse pregnancy outcome: a study from Pakistan. AJOG 2008;198(5):514.e1-8.

10. Darveau RP, Tanner A, Page RC. The microbiological challenges in periodonitis. Periodontol 2000 1997;14(1): 12-32.

11. Reed S. Potential public health implications of associations between periodontitis and reproductive outcomes. In: Public health implications of periodontal infections in adults-conference proceedings. J Public Health Dent 2005;65:63-4.

12. Mitchell-Lewis D, Engebreston SP, Chen J, et al. Periodontal infection and preterm birth: early findings from a cohort of young minority women in New York. Eur J Oral Sci 2001;109(1):34-9.

13. Lopez NJ, Smith PC, Guitereez J. Periodontal therapy may reduce risk of preterm low birth weight in women with periodontal disease: a randomized controlled trial. J Periodontal 2002;73(8):911-24. 
14. Jeffcoat MK, Hauth JC, Gereus NC, et al. Periodontal disease and preterm birth: results of pilot intervention study. J Peridontol 2003;74(8):1214-8.

15. Jeffcoat MK, Geurs NC, Reddy MS, et al. Periodontal infection and preterm birth. J Am Dent Assoc 2001;132(7):875-80.

16. Offenbacher S, Lieff $S$, Boggess KA, et al. Maternal periodontitis and prematurity. Part I: obstetric outcome of prematurity and growth restriction. Ann Periodontol 2001;6(1):164-74.

17. Louro PM, Fiori HH, Filho PL, et al. Periodontal disease in pregnancy and low birth weight. J Pediatr (Rio J) 2001;77(1):23-8.

18. Davenport ES, Williams CE, Sterne JA, et al. Maternal periodontal disease and preterm low birth weight: casecontrol study. J Dent Res 2002;81(5):313-8.

19. Lopez NJ, Smith PC, Gutierrez J. Higher risk of preterm birth and low birth weight in women with periodontal disease. J Dent Res 2002;81(1):58-63.

20. Jeffcoat MK, Hauth JC, Geurs NC, et al. Periodontal disease and preterm birth: results of a pilot intervention study. J Periodontol 2003;74(8):1214-8.

21. Goepfert AR, Jeffcoat MK, Andrews WW, et al. Periodontal disease and upper genital tract inflammation in early spontaneous preterm birth. Obstet Gynecol 2004;104(4): 777-83.

22. Mokeem SA, Molla GN, Al-Jewair TS. The prevalence and relationship between periodontal disease and pre-term low birth weight infants at King Khalid University hospital in Riyadh, Saudi Arabia. J Contemp Dent Practice 2004;5(2):40-56.

23. Michalowicz BS, Hodges JS, DiAngelis AJ, et al. Treatment of periodontal disease and the risk of preterm birth. $\mathrm{N}$ Engl J Med 2006;355(18):1885-94.

24. Srinivas SK, Sammel MD, Stamilio DM, et al. Periodontal disease and adverse pregnancy outcomes: is there an association? Am J Obstet Gynecol 2009;200(5):497.e1-8.
25. Offenbacher S, Beck JD, Jared HL, et al. Maternal Oral Therapy to Reduce Obstetric Risk (MOTOR) Investigators. Effects of periodontal therapy on rate of preterm delivery: a randomized controlled trial. Obstet Gynecol 2009;114(3):551-9.

26. Lunardelli AN, Peres MA. Is there an association between periodontal disease, prematurity and low birth weight? A population-based study. J Clin Periodontol 2005;32(9):938-46.

27. Gomes-Filho IS, Cruz SS, Rezende EJ, et al. Exposure measurement in the association between periodontal disease and prematurity/low birth weight. J Clin Periodontol 2007;34(11):957-63.

28. Khader Y, Al-shishani L, Obeidat B, et al. Maternal periodontal status and preterm low birth weight delivery: a case-control study. Arch Gynecol Obstet 2009;279(2): 165-9.

29. Polyzos NP, Polyzos IP, Mauri D, et al. Effect of periodontal disease treatment during pregnancy on preterm birth incidence: a metaanalysis of randomized trials. Am J Obstet Gynecol 2009;200(3):225-32.

30. Polyzos NP, Polyzos IP, Zavos A, et al. Obstetric outcomes after treatment of periodontal disease during pregnancy: systematic review and meta-analysis. BMJ 2010; 341: c7017.

31. Vogt M, Sallum AW, Cecatti JG, et al. Periodontal disease and some adverse perinatal outcomes in a cohort of low risk pregnant women. Reprod Health 2010;7:29.

32. Siqueira FM, Cota LO, Costa JE, et al. Intrauterine growth restriction, low birth weight, and preterm birth: adverse pregnancy outcomes and their association with maternal periodontitis. J Periodontol 2007;78(12):2266-76.

33. Sasahara J, Kikuchi A, Takakuwa K, et al. Antibody responses to Porphyromonasgingivalis outer membrane protein in the first trimester. Aust $\mathrm{N}$ Z J Obstet Gynaecology 2009;49(2):137-41. 